\title{
Expected Future Precipitation in Central Iraq Using LARS-WG Stochastic Weather Generator
}

\author{
Yassin Osman1, Nadhir Al-Ansari², Mawada Abdellatif', Sadeq B. Aljawad4, \\ Sven Knutsson ${ }^{2}$ \\ ${ }^{1}$ University of Bolton, Bolton, UK, \\ ${ }^{2}$ Lulea University of Technology, Lulea, Sweden \\ ${ }^{3}$ Liverpool JM University, Liverpool, UK \\ ${ }^{4}$ Water Resources, The Prime Minister Office, Baghdad, Iraq \\ Email: y.osman@bolton.ac.uk, nadhir.alansari@ltu.se, M.E.Abdellatif@ljmu.ac.uk, sb jawad@yahoo.com, \\ Sven.Knutsson@ltu.se
}

Received 4 October 2014; revised 18 November 2014; accepted 2 December 2014

Copyright (C) 2014 by authors and Scientific Research Publishing Inc.

This work is licensed under the Creative Commons Attribution International License (CC BY).

http://creativecommons.org/licenses/by/4.0/

(c) (†) Open Access

\section{Abstract}

The Middle East (ME) is characterized by its water shortage problem. This region with its arid climate is expected to be the most vulnerable in the world to the potential impacts of climate change. Iraq (located in ME) is seriously experiencing water shortage problem. To overcome this problem rain water harvesting can be used. In this study the applicability of the long-term weather generator model in downscaling daily precipitation Central Iraq is used to project future changes of precipitation based on scenario of seven General Circulation Models (GCMs) outputs for the periods of 2011-2030, 2046-2065, and 2080-2099. The results indicated that December-February and September-November periods, based on the ensemble mean of seven GCMs, showed an increasing trend in the periods considered; however, a decreasing trend can be found in March, April, and May in the future.

\section{Keywords}

Iraq, Baghdad, Climate Change, Statistical Downscaling, Global Climate Models, LARS-WG

\section{Introduction}

Climate change is considered to be the biggest challenge facing by the mankind in the twenty first century. The 
change in the climate mean state within a certain time period is referred to as climate variability which can be more detrimental than the climate change. Both climate variability and change can lead to severe impacts on different major sectors of the world such as water resources, agriculture, energy and tourism.

Iraq was considered rich in its water resources compared with other countries where the annual allocation per capita reached $6029 \mathrm{~m}^{3}$ in 1995 and expected to be $2100 \mathrm{~m}^{3}$ in 2015 [1]. However, construction of dams on the Tigris and Euphrates and their tributaries outside the border of Iraq, the effect of global climate change and mismanagement of water resources are the main factors in the water shortage problems in Iraq [2] [3]. Restoring the marshes [3]-[5] and the growing demand for water in Turkey and Syria will lead to drying up the Tigris and Euphrates Rivers in 2040 [4]. One of the solutions to overcome the water shortage crises is to use non-conventional water resources (e.g. water harvesting) and to apply such techniques the spatial distribution and intensity of rainfall events are required [3] [6]-[12].

To develop strategies and make informed decisions about the future water allocation for different sectors and management of available water resources, they need climate change information (usually in terms of watershed scale precipitation and temperature) that can directly be used by the hydrologic impact models. Atmosphereocean coupled Global Climate Models (GCMs) are the main source to simulate the present and project the future climate of the earth under different climate change scenarios (e.g. Special Report on Emission Scenarios SRES 2000). The computational grid of the GCMs is very coarse (a grid box covers more than $40,000 \mathrm{~km}^{2}$ ), and thus they are unable to skillfully model the sub-grid scale climate features like topography or clouds of the area in question [13]. Consequently, GCMs to date are unable to provide reliable information of rainfall for hydrological modelling. Thus, there is a need for downscaling, from coarse resolution of the GCM to a very fine resolution or even at a station scale. The downscaling methodologies developed to date can be broadly categorized as statistical and dynamical. Among the statistical downscaling methods, the use of stochastic weather generators is very popular. They are not computationally demanding, simple to apply and provide station scale climate change information [14] [15].

Weather generators are classified as statistical models used to generate a long synthetic series of data, fill in missing data and produce different realizations of the same data [16]. They employ random number generators and use the observed time series of a station/site as input. Stochastic weather simulation is not new and has a history starting from 1950s, as reported by Racsko et al. [17]. Among some researchers who contributed to its evolution are [18]-[23]. Wilby [16] has presented a comprehensive review of its theory and evolution over time. Weather generators have been employed to get long time series of hydro-meteorological variables which can be used, for example, by crop growth model to forecast agricultural production (e.g. [24] [25]) and assessment of risk associated with climate variability [26]. Further details on the use of weather generator in crop production studies can be found in Semenov [27]. When the climate changes research community started looking for low cost, computationally less expensive and quick methods for impact assessment, the weather generator emerged as a most suitable solution (e.g. [28] [29]). Long Ashton Research Station Weather Generator (LARS-WG) is a stochastic weather generator specially designed for climate change impact studies [30]. It has been tested for diverse climates and found better than some other generators [31]. A recent study by Semenov [32] has tested LARS-WG for different sites across the world and has shown its ability to model rainfall extremes with reasonable skill.

It has been reported in the Climate Change IPCC AR4 (2007) [33] that climate change is likely to affect the mean as well as variability of precipitation across the world. Change in variability and precipitation extremes can seriously affect the sustainable management of urban water infrastructure in big cities, such as Baghdad. If a weather generator is adequately skilful in simulating the mean as well as extreme properties of precipitation, such as wet/dry spell length and annual maximum (AM) precipitation, it can be adopted as a simplified, computationally inexpensive global solution for incorporating climate change information into decision making for planning sustainable infrastructure of a big city.

The main objective of the present study is to project future precipitation in the Central Iraq region city of Baghdad which can be used for impact assessments that require local-scale climate scenarios. The approach is based on the LARS-WG weather generator (Semenov 2007, 2008). A new version of the software is described, which incorporates predictions from the IPCC AR4 multi-model ensemble (Table 1). Given site parameters derived from observed daily weather, WG can generate local-scale daily climate scenarios for the future at any location in the world consistent with the AR4 climate perditions. By treating each GCM prediction from the AR4 ensemble as an equally possible evolution of climate, we can explore the uncertainty in impact assessment resulting from the uncertainty in climate predictions. The results will also help decision makers and researchers in 
Table 1. Selected 7 global climate models from IPCC AR4 incorporated into the LARS-WG 5.5 in this study.

\begin{tabular}{cccc}
\hline No. & GCM & Research center & Grid \\
\hline 1 & CNCM3 & Centre National de Researches France & $1.9^{\circ} \times 1.9^{\circ}$ \\
2 & GFCM21 & Geophysical Fluid Dynamics Lab USA & $2.0^{\circ} \times 2.5^{\circ}$ \\
3 & HADCM3 & UK Meteorological Office UK & $2.5^{\circ} \times 3.75^{\circ}$ \\
4 & INCM3 & Institute for Numerical Mathematics Russia & $4^{\circ} \times 5^{\circ}$ \\
5 & IPCM4 & Institute Pierre Simon Laplace France & $2.5^{\circ} \times 3.75^{\circ}$ \\
6 & MPEH5 & Max-Planck Institute for Meteorology Germany & $1.9^{\circ} \times 1.9^{\circ}$ \\
7 & NCCCS & National Centre for Atmospheric USA & $1.4^{\circ} \times 1.4^{\circ}$ \\
\hline
\end{tabular}

future planning for the water resources in Iraq and help in finding ways and means to minimize the effect of climate change on the inhabitants and the environment.

\section{Study Area and Data}

Baghdad is the capital of Iraq. It covers an area of $204.2 \mathrm{~km}^{2}$. Its population is more than 7.5 million. It is located on the River Tigris in the central part of Iraq. In this study, data from central Bagdad rain gauge (shown in Figure 1, Lat: $33.325^{\circ}$, Lon: $44.42^{\circ}$, Alt: $\left.41 \mathrm{~m}\right)$ is used. The daily rainfall data is available for period 1941 to 2002. But only data in period 1961-2000 (40 years) is selected for analysis as required for the calibration of the weather generator. In climate change studies, this period is used to represent the current or baseline climate (cf. [13]). The rainfall data used in this study was obtained from the Iraqi National Meteorological Organisation.

The annual rainfall in Iraq varies where it reaches $150 \mathrm{~mm}$ within the western desert, more than $1000 \mathrm{~mm}$ within the mountains at the north to about $200 \mathrm{~mm}$ at the eastern part of the country [3] [6] [7] [34]. The overall average annual rainfall is of the order of $213 \mathrm{~mm}$ per year. The rainy season begins in October and ends in May. The central region of Iraq is characterised by a rainy season that roughly starts in October and continues all the way until May of the following year. During the rainy season, rainfall can be heavier during October and January and lighter in between. However, the summer period (June, July and August) are described as a dry period in which rain has rarely recorded. Figure 2 shows a typical rainy season in Bagdad for the rainy year 1965/1966.

In order to predict the local precipitation data, large scale predictors simulated by GCMs are needed. In the new version of the LARS-WG, predictions based on various emission scenarios from 15 GCMs used in the IPCC AR4 have been incorporated. Considering the civil situation of Iraq, SRA2 emission scenario that pays more attention to local tradition and population growth was chosen in this study. Among the 15 GCMs, seven of them had SRA2 scenario and were used to predict the future change of local-scale precipitation in three periods: 2011-2030, 2046-2065, and 2080-2099 (as listed in Table 1).

\section{Methodology}

\subsection{Description of LARS-WG Model}

LARS-WG is a stochastic weather generator and used for simulating weather data at a single site under both current and future conditions [17] [30] [31] [35]. LARS-WG uses observed daily weather data for a given site to compute a set of parameters for probability distributions of weather variables as well as well as correlation between them, which are used to generate synthetic weather time series of arbitrary length by randomly selecting values from the appropriate distributions. To approximate probability distributions of dry and wet series of daily precipitation, Tmax and Tmin, LARS-WG uses a semiemprical distribution (SED) that is defined as the cumulative probability distribution function (CDF). The number of intervals ( $n$ ) used in SED is 23 in the new version (Version 5.0), which offers more accurate representation of the observed distribution compared with the ten used in the previous version. For each climatic variable $v$, a value of climatic variable vi corresponding to the probability $p i$ is calculated as: 


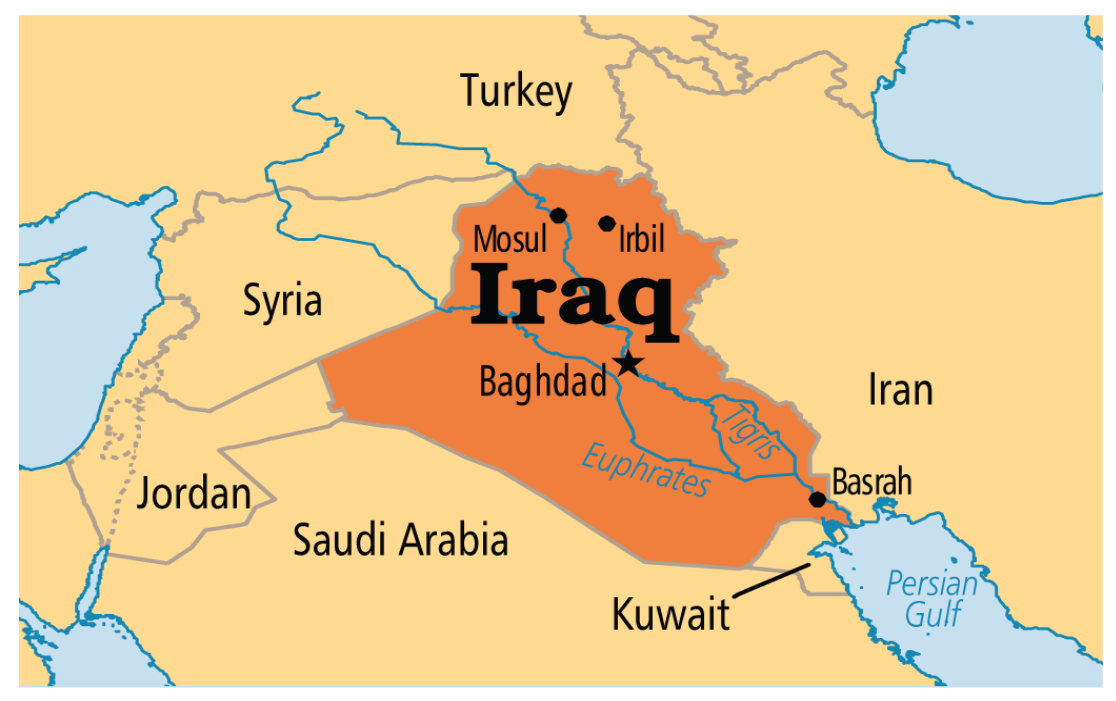

Figure 1. Location map of study area.

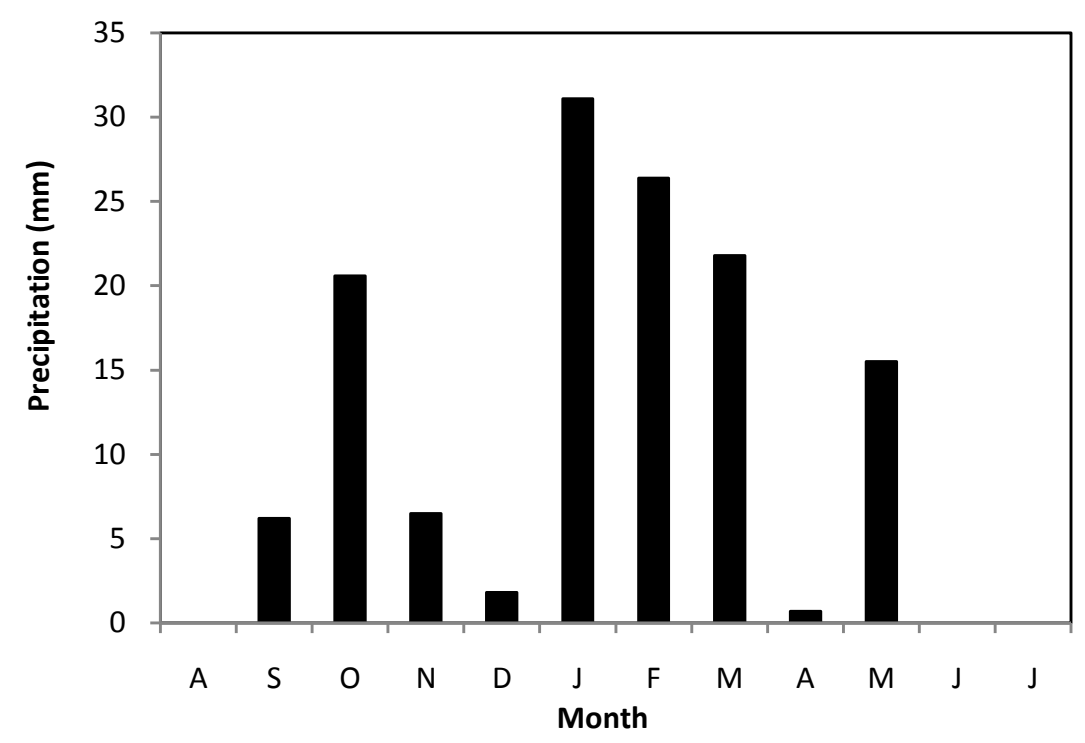

Figure 2. Typical rainy season in Bagdad (Year 1965/1966).

$$
v i=\min \left\{v: P\left(v_{o b s} \leq v\right) \geq p i\right\} i=0, \ldots ., n
$$

where $P()$ denotes probability based on observed data $\left\{v_{o b s}\right\}$. For each climatic variable, two values, $p_{0}$ and $p_{n}$ are fixed as $p_{0}=0$ and $p_{n}=1$, with corresponding values of $v_{0}=\min \left\{v_{o b s}\right\}$ and $v_{n}=\max \left\{v_{o b s}\right\}$. To approximate the extreme values of a climatic variable accurately, some pi are assigned close to 0 for extremely low values of the variable and close to 1 for extremely high values; the remaining values of pi are distributed evenly on the probability scale.

Because the probability of very low daily precipitation $(<1 \mathrm{~mm})$ is typically relatively high and such low precipitation has very little effect on the output of a process-based impact model, we used only two values, $v_{1}=0.5$ $\mathrm{mm}$ and $v_{2}=1 \mathrm{~mm}$ to approximate precipitation within the interval $[0,1]$ with the corresponding probabilities calculated as $p i=P\left(v_{o b s} \leq v i\right) i=1,2$. To account for extremely high long dry and wet series, two values close to 1 are used in SEDs for wet and dry series, $p_{n-1}=0.99$ and $p_{n-2}=0.98$.

For maximum and minimum temperatures, two values close to 0 and two close to 1 are used to account for extremely low and high temperatures, i.e., $p_{2}=0.01, p_{3}=0.02, p_{n-1}=0.99$ and $p_{n-2}=0.98$. All pi values $(0<I<$ $n)$. In the new version of LARS-WG (5.5), the maximum and minimum temperature for dry and wet days are 
approximated by SEDs calculated for each month [35] [36].

\subsection{Outline of the Stochastic Weather Generator Process LARS-WG}

In LARS-WG, the process of generating synthetic weather data can be divided into three distinct steps, which are briefly described as follows. More detailed description of the modelling procedure can be referred to [37].

-Model calibration

Model calibration is done to use the function "SITE ANALYSIS" in LARS-WG, which analyses observed weather data (e.g., precipitation and maximum and minimum temperature) to determine their statistical characteristics and store this information in two parameter files.

-Model validation

The parameter files derived from observed weather data during the model calibration process are used to generate synthetic weather data having the same statistical characteristics as the original observed data. Model validation is to analyse and compare the statistical characteristics of the observed and synthetic weather data to assess the ability of LARS-WG to simulate the precipitation at the chosen sites in order to determine whether or not it is suitable for use.

\subsection{Generation of Synthetic Weather Data}

The parameter files derived from the observed weather data during the model calibration process can also be used to generate synthetic data corresponding to a particular climate change scenario simulated by GCMs.

\subsection{Generation of Climate Scenario}

By perturbing parameters of distributions for a site with the predicted changes of climate derived from global or regional climate models, a daily climate scenario for this site could be generated and used in conjunction with a process-based impact model for assessment of impacts. To generate climate scenarios at a site for a certain future period and an emission scenario, the LARS-WG baseline parameters, which are calculated from observed weather for this site for a baseline period, for instance 1961-2000, are adjusted by the $\Delta$-changes for the future period and the emissions predicted by a GCM for each climatic variable for the grid covering the site. In this study, the local-scale climate scenarios based on the SRA2 scenario simulated by the selected seven GCMs are generated by using LARS-WG (5.5) for the time periods of 2011-2030 (T1), 2046-2065 (T2), and 2080-2099 (T3) to predict the future change of precipitation in Baghdad. Semenov and Stratonovich (2010) introduced and used the procedure to generate the local-scale climate scenarios based on the IPCC AR4 multi-model ensemble to assess the changes in probability of heat stress around flowering for wheat at several locations in Europe.

\section{Results and Discussion}

\subsection{Results of Calibration and Validation of LARS-WG}

The daily precipitation data for Baghdad for the period 1961-2000 (40 years) was used to calibrate and validate the model for the region. To assess the ability of LARS-WG, in addition to the graphic comparison, some statistical tests are also performed. The Kolmogorov-Smirnov (K-S) test is performed on testing equality of the seasonal distributions of wet and dry series (WDSeries) and distributions of daily rainfall (RainD) calculated from observed data and downscaled data. The test calculates a p-value, which is used to accept or reject the hypotheses that the two sets of data could have come from the same distribution (i.e., when there is no difference between the observed and simulated climate for that variable). A very low p-value, and a corresponding high K$\mathrm{S}$ value means the simulated climate is unlikely to be the same as the observed climate; hence must be rejected. Although a p-value of 0.05 is the common significance level used in most statistics, the authors Semenov and Barrow [30] of the model suggests a p-value of 0.01 be used as the acceptable significance limit of the model results. Significant differences between the observed and simulated data may arise from the model smoothing the observed data, errors in the observed data, random variation in the observed data, and unusual climate phenomenon at a climate station making a particular year's climate very different. Table 2 shows the statistical analyses results of the model's performance in simulating the seasonal observed data and Table 3 shows the 
model performance for simulating the daily rain in each month. In both tables, the letter "N" represents the number of test carried.

Assessment of the LARS-WG performance in simulating the seasonal precipitation in Baghdad is inserted in the "Assessment" column in Table 2. It can be clearly observed from this assessment that the model performs very well in fitting the winter "DJF" and autumn "SON" precipitation as fitting of the wet and dry spells series distributions in these two seasons are either very good or perfect. The model performance in fitting of the wet and dry spells series distributions in the spring "MAM" season is also assessed as good to perfect for the distribution of the wet and dry spells, respectively. However, the model performance in fitting the distributions of wet/dry spells series in the summer "JJA" season is somewhat difference. While the model performs very well in fitting the dry spell distribution, it performs poorly in fitting the wet spell one. The reason for the poor performance here is attributed to the summer season being a dry one. As there is no or rare rain recorded in this season (cf. Section 2 and Figure 2), the weather generator would not be able to fit any wet spell and thus it would perform poorly.

Similarly, assessment of LARS-WG performance in simulating the daily rain in each month is inserted in the

\section{Table 2. K-S-test for seasonal wet/dry SERIES distributions.}

\begin{tabular}{cccccc}
\hline Season & Wet/Dry & $\mathrm{N}$ & K-S & p-Value & Assessment \\
\hline DJF & Wet & 12 & 0.050 & 1.000 & Perfect fit \\
& Dry & 12 & 0.157 & 0.916 & Gery good fit \\
MAM & Wet & 12 & 0.231 & 0.514 & Peod fit \\
& Dry & 12 & 0.068 & 1.000 & Poor fit \\
JJA & Wet & 12 & 0.913 & 0.000 & Very good fit \\
& Dry & 12 & 0.130 & 0.984 & Very good fit \\
\hline
\end{tabular}

Table 3. K-S-test for daily RAIN distributions.

\begin{tabular}{|c|c|c|c|c|}
\hline Month & $\mathrm{N}$ & $\mathrm{K}-\mathrm{S}$ & p-Value & Assessment \\
\hline $\mathrm{J}$ & 12 & 0.110 & 0.998 & Perfect fit \\
\hline $\mathrm{F}$ & 12 & 0.024 & 1.000 & Perfect fit \\
\hline M & 12 & 0.048 & 1.000 & Perfect fit \\
\hline A & 12 & 0.037 & 1.000 & Perfect fit \\
\hline M & 12 & 0.119 & 0.994 & Perfect fit \\
\hline $\mathrm{J}$ & 12 & 0.500 & 0.004 & Poor fit \\
\hline $\mathrm{J}$ & 12 & 0.957 & 0.000 & Poor fit \\
\hline A & \multicolumn{4}{|c|}{ No precipitation } \\
\hline $\mathrm{S}$ & 12 & 0.397 & 0.038 & Moderate fit \\
\hline $\mathrm{O}$ & 12 & 0.049 & 1.000 & Perfect fit \\
\hline $\mathrm{N}$ & 12 & 0.03 & 1.000 & Perfect fit \\
\hline $\mathrm{D}$ & 12 & 0.063 & 1.000 & Perfect fit \\
\hline
\end{tabular}


“Assessment” column in Table 3. The assessment results show that LARS-WG performance in simulating distributions of the daily rain in all months is perfect except in the months of the summer season. The reason for poor performance here is as given previously in the case of poor performance in modelling the seasonal distribution of wet/dry days.

From the results in Table 2 and Table 3, it can be noted that LARS-WG is more capable in simulating the seasonal distributions of the wet/dry spells and the daily precipitation distributions in each month. These two properties are very important when using the model results in impact studies.

To increase confidence in LARS-WG capability for predicting future precipitation, comparisons between statistics calculated from simulated precipitation with the corresponding ones calculated from the observed data are carried here. Figure 3 shows comparison between the monthly mean and standard deviation yielded by the two series. Figure 3 reveals a very good performance of LARS-WG in fitting both statistics. Overall, the mean monthly totals are very well modelled by LARS-WG. In terms of standard deviation, LARS-WG shows an excellent performance, except for March and April where LARS-WG slightly underestimates the standard deviation.

The simulation of wet/dry spell lengths is very important, as it can be used for the assessment of drought risk or drainage network efficiency of a big city. The simulation results of LARS-WG are shown in Figure 4(a) and Figure 4(b) for wet and dry spell lengths, respectively. Examination of Figure 4(a) and Figure 4(b) show LARS-WG has a remarkable skill in simulating wet and dry spells' lengths, as the lines representing observed and simulated values are almost overlapping throughout.

Comparison of the observed and the LARS-WG simulated 40-year annual maximum series is shown in Figure 5. As explained earlier, LARS-WG generates random data which is comparable to the observed data in its statistical properties only. Examination of Figure 5 shows that both the observed and simulated values are of the same order which indicates good performance of LARS-WG simulation.

Based on the above analysis and comparisons, it can be concluded that the LARS-WG model has very good performance in generating daily and extreme precipitation in Baghdad and can reasonably be used to predict daily precipitation for near, medium and far future for purposes of impact studies.

\subsection{Generation of Future Precipitation Scenarios}

The calibrated LARS-WG for Baghdad found above was then used to predict daily precipitation is Central Iraq for the periods of 2011-2030 (near future), 2046-2065 (medium future), and 2080-2099 (far future) based on the SRA2 scenarios generated from seven GCMs (cf. Table 1).

The results of the precipitation prediction by using LARS-WG were plotted on Figure 6 and Figure 7.

In Figure 6, the box-whisker plots showed the distribution of precipitation downscaled from seven GCMs by using LARS-WG in the periods of 2011-2030, 2046-2065, and 2080-2099 comparing with the current observation (1961-2000). The plot elements and the statistics are as follows: the length of the box represents the inter-

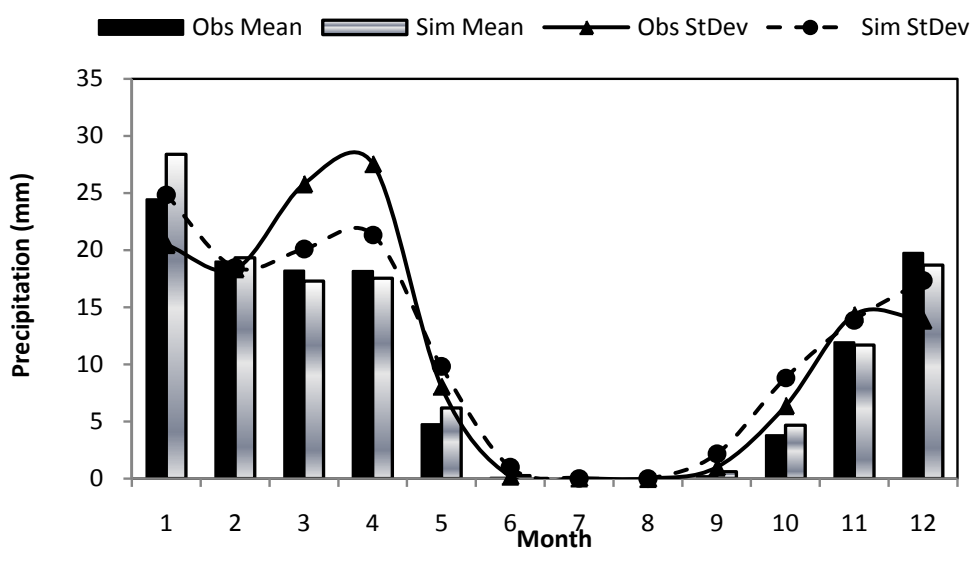

Figure 3. Observed and simulated mean and standard deviation of precipitation at study site. 


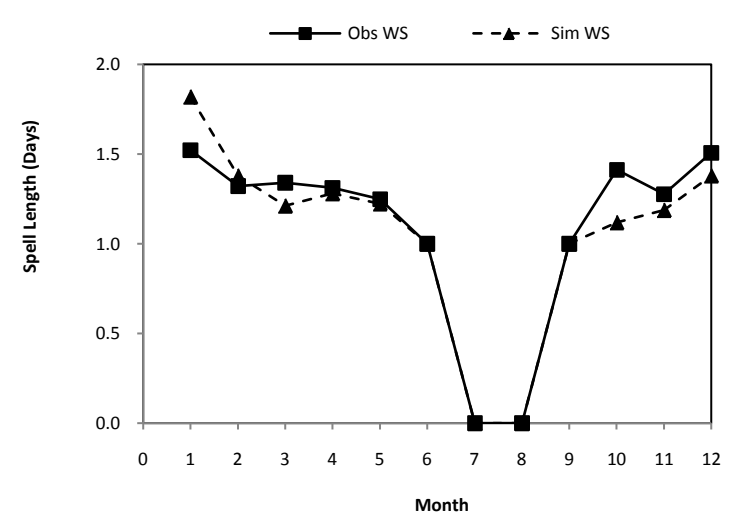

(a)

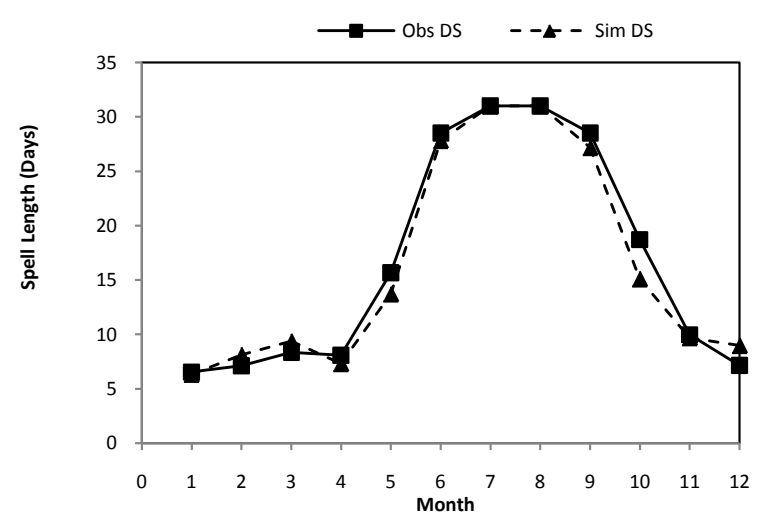

(b)

Figure 4. (a) Observed and simulated wet spell; (b) Observed and simulated dry spell.

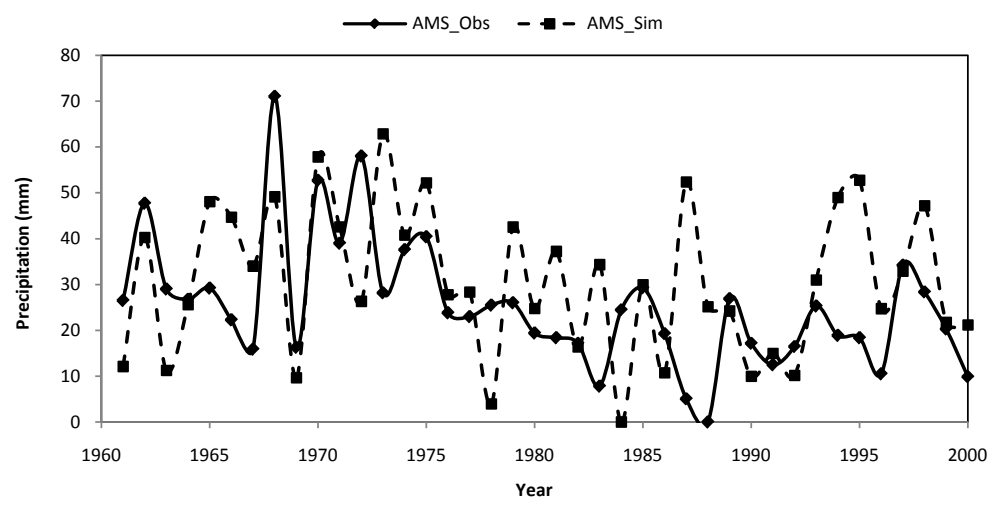

Figure 5. Observed and simulated annual maximum series.

quartile range (the distance between the 25th and 75th percentiles), the horizontal line in the box interior represents the group median, and the vertical lines (called whiskers) issuing from the box extends to the group minimum and maximum values. In Figure 6, each box-whisker plot represents the prediction from one GCM and it is easy to find that in Figure 6(a) there are a coherent change trends among various GCMs' predictions (5 out of 7) of mean precipitation during 2011-2030, which is a slight to no change in Central Iraq precipitation in the near future compared to the baseline period. In Figure 6(b), the precipitation predictions from INCM3, MPEH5 and NCCCS are more than the value of the baseline period; however, those from CNCM3, GFCM21, HADCM3 and IPCM4, are less than or close to the value of the baseline period. This indicates that there are great uncertainties in predicting the future precipitation by using a single GCM. Based on plots of Figure 6(b), the likely prediction of future precipitation in Central Iraq in the medium future is a slight reduction to no change in precipitation compared to the baseline period. For the prediction of precipitation in the far future shown in Figure 6(c), there are consistent trends among the seven GCM models to predict precipitation less than the value of baseline period except those from CNCM3 which showed great differences of predictions from the other six. Therefore, the likely prediction of future precipitation in Central Iraq in the far future is a pronounced reduction in precipitation compared to the baseline period.

The ensemble means of precipitation predictions from seven GCMs were calculated to further illustrate the future change in the period of 2011-2030, 2046-2065, and 2080-2099, and the differences between the ensemble means and the baseline value for the seasonal precipitation were plotted in Figure 7 for the periods of 20112030, 2046-2065, and 2080-2099. In Figure 7, it can be seen that in Central Iraq, the precipitation in DJF (December, January, and February) shows an increasing trend in the periods of 2011-2030 and 2046-2065, and a decreasing trend in period 2080-2099. This result is consistent with other early studies in Iraq [8] [34]. For the precipitation in MAM (March, April, and May) the plot shows a reduction trend in all considered future periods with the reduction projected to be very significant towards the far future. The future is also going to witness no 


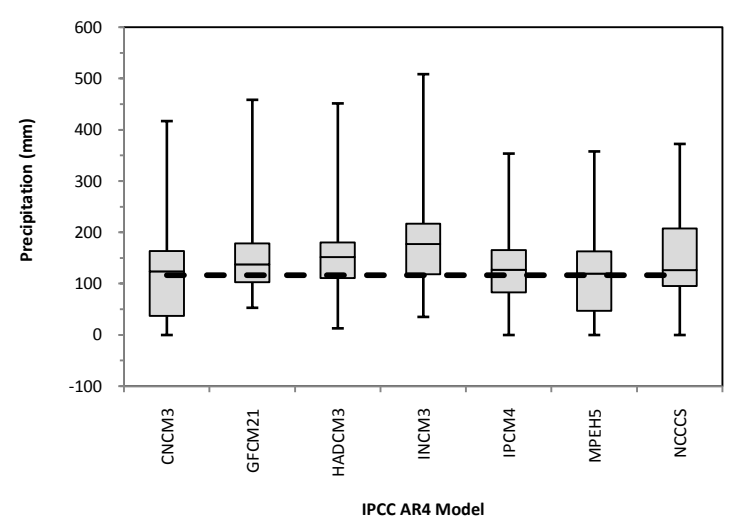

(a)

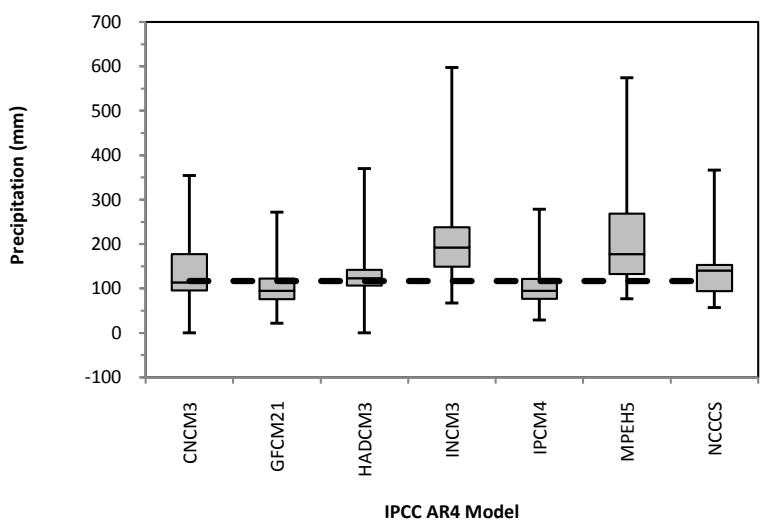

(b)

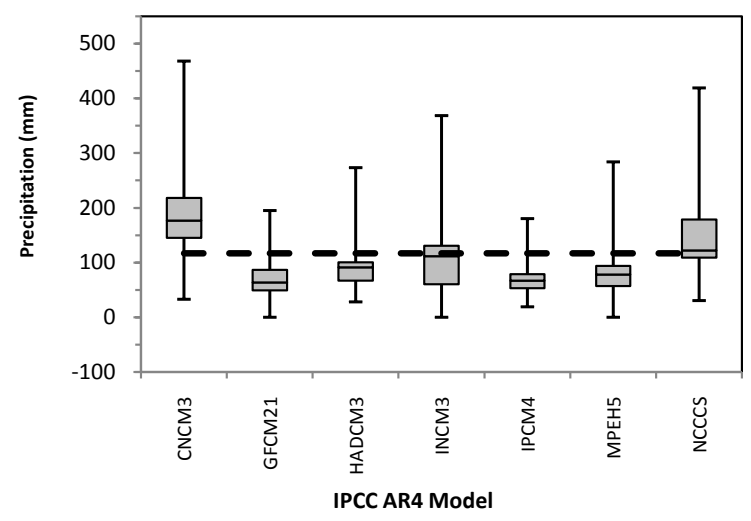

(c)

Figure 6. Box-whisker plots for change in future precipitation in Central Iraq downscaled from 7 GCMs by LARS-WG during (a) 2011-2030, (b) 2046-2065, and (c) 2080-2099 compared to the current period (1961-2000) shown in a dashed line.

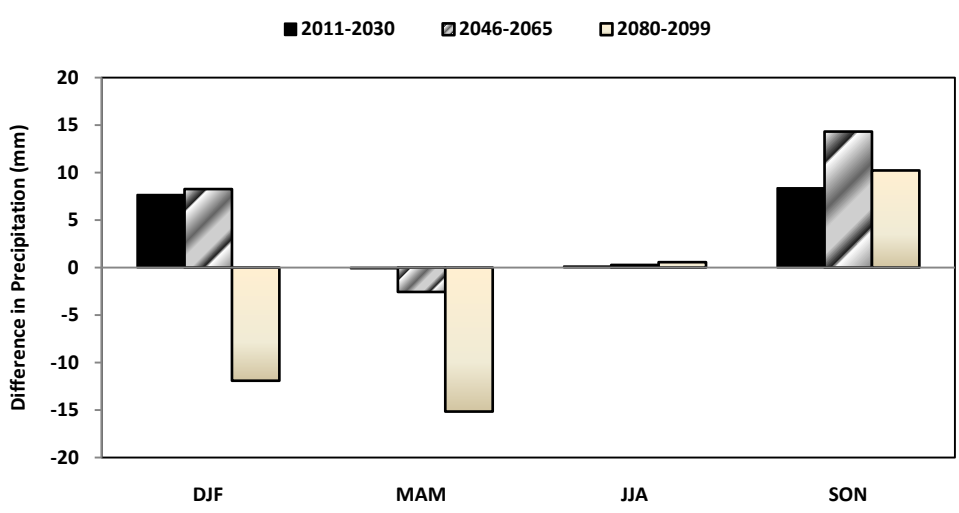

Figure 7. The differences of precipitation between the future periods (20112030, 2046-265, and 2080-2099) and the current period (1961-2000) in Central Iraq.

or rare rain during the JJA (June, July, and August). An obvious increasing trend of precipitation in SON (September, October, and November) is projected in Central Iraq in the future. From the above discussions, it can be inferred that Central Iraq has different change trends of precipitation in the rainy seasons in the future.

\section{Conclusions}

In the present study, we first tested the applicability of the LARS-WG model in downscaling daily precipitation 
in Central Iraq and then used LARS-WG to predict future changes of precipitation in Central Iraq from the seven GCM outputs of SRA2 scenario for the periods of 2011-2030, 2046-2065, and 2080-2099. Data for the period of 1961 to 2000 were used for calibrating the downscaling model and for comparison with future scenarios. From the study, it is concluded that:

- The LARS-WG model has reasonable skill to simulate the daily and extreme precipitation and can be adopted as an effective tool for incorporating climate change impacts into sustainable development;

- The downscaled precipitation from the predictions of seven GCMs has different changing trends in the future three periods. This also illustrates that more GCMs should be considered in the study of climate change to reduce the uncertainty of GCMs;

- The precipitation prediction in two of the three rainy seasons in Central Iraq, DJF \& SON, shows an increasing trend in the future, while in the third season (MAM) it shows a decreasing trend in the future. The later prediction could bring difficulty in the region's agriculture productivity and water supply during MAM season. This can enhance the use of water harvesting techniques to minimize the water shortage problem.

\section{Acknowledgements}

The research presented has been financially supported by Luleå University of Technology, Sweden and by "Swedish Hydropower Centre-SVC" established by the Swedish Energy Agency, Elforsk and Svenska Kraftnät together with Luleå University of Technology, The Royal Institute of Technology, Chalmers University of Technology and Uppsala University. Their support is highly appreciated. Thanks to the Iraqi Metrological Office for providing the data.

\section{References}

[1] Nimah, M.N. (2008) Water Resources (2008) Report of the Arab Forum for Environment and Development. In: Tolba M.K. and Saab, N.W., Eds., Arab Environment and Future Challenges, Chapter 5, Arab Forum for Environment and Development, Cairo, 63-74.

[2] Al-Ansari, N.A. (2013) Management of Water Resources in Iraq: Perspectives and Prognoses. Engineering, 5, 667-668. http://dx.doi.org/10.4236/eng.2013.58080

[3] Al-Ansari, N.A., Ali, A. and Knutsson, S. (2014) Present Conditions and Future Challenges of Water Resources Problems in Iraq. Journal of Water Resource and Protection, 6, 1066-1098. http://dx.doi.org/10.4236/jwarp.2014.612102

[4] UN (2010) Water Resources Management White Paper, United Nations Assistance Mission for Iraq, United Nations Country Team in Iraq. 20 p. http://iq.one.un.org/documents/100/white\%20paper-eng_Small.pdf

[5] Al-Ansari, N.A., Knutsson, S. and Ali, A. (2012) Restoring the Garden of Eden, Iraq. Journal of Earth Sciences and Geotechnical Engineering, 2, 53-88.

[6] Al-Ansari, N.A., Ezz-Aldeen, M., Knutsson, S. and Zakaria, S. (2013) Water Harvesting and Reservoir Optimization in Selected Areas of South Sinjar Mountain, Iraq. Journal of Hydrologic Engineering, 18, 1607-1616. http://dx.doi.org/10.1061/(ASCE)HE.1943-5584.0000712

[7] Al-Ansari, N.A., Zakaria, S., Mustafa, Y.T., Ahmad, P., Ghafour, B. and Knutsson, S. (2013) Development of Water Resources in Koya City, Iraq. 1st International Symposium on Urban Development of Koya, Koya City, 16-17 December 2013, 91-98. http://dx.doi.org/10.2495/ISUD130111

[8] Zakaria, S. (2014) Rainwater Harvesting (RWH) North of Iraq. Ph.D. Thesis, Lulea University of Technology, Lulea.

[9] Zakaria, S., Al-Ansari, N., Mustafa, Y., Alshibli, M. and Knutsson, S. (2013) Macro Rain Water Harvesting Network to Estimate Annual Runoff at Koysinjaq (Koya) District, Kurdistan Region of Iraq. Engineering, 5, 956-966. http://dx.doi.org/10.4236/eng.2013.512117

[10] Zakaria, S., Al-Ansari, N.A., Mustafa, Y., Mohammed, D.A., Knutsson, S., Ahmed, P. and Ghafour, B. (2013) Rainwater Harvesting at Koysinjaq (Koya), Kurdistan Region, Iraq. Journal of Earth Sciences and Geotechnical Engineering, 3, 25-46.

[11] Zakaria, S., Al-Ansari, N.A. and Knutsson, S. (2013) Historical and Future Climatic Change Scenarios for Temperature and Rainfall for Iraq. Journal of Civil Engineering and Architecture, 7, 1574-1594.

[12] Zakaria, S., Al-Ansari, N. and Knutsson, S. (2013) Wheat Yield Scenarios for Rainwater Harvesting at Northern Sinjar Mountain, Iraq. Natural Science, 5, 1057-1068. http://dx.doi.org/10.4236/ns.2013.510130

[13] Wilby, R.L., Dawson, C.W. and Barrow, E.M. (2002) SDSM-A Decision Support Tool for the Assessment of Regional Climate Change Impacts. Environmental Modelling \& Software, 17, 145-157. 
http://dx.doi.org/10.1016/S1364-8152(01)00060-3

[14] Dibike, Y.B. and Coulibaly, P. (2005) Hydrologic Impact of Climate Change in the Saguenay Watershed: Comparison of Downscaling Methods and Hydrologic Models. Journal of Hydrology, 307, 145-163. http://dx.doi.org/10.1016/j.jhydrol.2004.10.012

[15] Kilsby, C.G., Jones, P.D., Burton, A., Ford, A.C., Fowler, H.J., Harpham, C., James, P., Smith, A. and Wilby, R.L. (2007) A Daily Weather Generator for Use in Climate Change Studies. Environmental Modelling and Software, 22, 1705-1719. http://dx.doi.org/10.1016/j.envsoft.2007.02.005

[16] Wilks, D.S. and Wilby, R.L. (1999) The Weather Generation Game: A Review of Stochastic Weather Models. Progress in Physical Geography, 23, 329-357. http://dx.doi.org/10.1177/030913339902300302

[17] Racsko, P., Szeidl, L. and Semenov, M. (1991) A Serial Approach to Local Stochastic Weather Models. Ecological Modelling, 57, 27-41. http://dx.doi.org/10.1016/0304-3800(91)90053-4

[18] Bruhn, J.A., Fry, W.E. and Fick, G.W. (1980) Simulation of Daily Weather Data Using Theoretical Probability Distributions. Journal of Applied Meteorology, 19, 1029-1036. http://dx.doi.org/10.1175/1520-0450(1980)019<1029:SODWDU>2.0.CO;2

[19] Bruhn, J.A. (1980) A Stochastic Model for the Simulation of Daily Weather. Protection Ecology, 2, 199-208.

[20] Nicks, A.D. and Harp, J.F. (1980) Stochastic Generation of Temperature and Solar Radiation Data. Journal of Hydrology, 48, 1-17. http://dx.doi.org/10.1016/0022-1694(80)90062-1

[21] Richardson, C.W. (1981) Stochastic Simulation of Daily Precipitation, Temperature, and Solar Radiation. Water Resources Research, 17, 182-190. http://dx.doi.org/10.1029/WR017i001p00182

[22] Richardson, C.W. and Wright, D.A. (1984) WGEN: A Model for Generating Daily Weather Variables. US Department of Agriculture, Agricultural Research Service, ARS-8, United States Department of Agriculture, Agricultural Research Services, Washington DC, 83 p.

[23] Schoof, J.T., Arguez, A., Brolley, J. and O’Brien, J.J. (2005) A New Weather Generator Based on Spectral Properties of Surface Air Temperatures. Agricultural and Forest Meteorology, 135, 241-251. http://dx.doi.org/10.1016/j.agrformet.2005.12.004

[24] Riha, S.J., Wilks, D.S. and Simoens, P. (1996) Impact of Temperature and Precipitation Variability on Crop Model Predictions. Climatic Change, 32, 293-311. http://dx.doi.org/10.1007/BF00142466

[25] Hartkamp, A.D., White, J.W. and Hoogentoom, G. (2003) Comparison of Three Weather Generators for Crop Modelling: A Case Study for Subtropical Environments. Agricultural Systems, 76, 539-560. http://dx.doi.org/10.1016/S0308-521X(01)00108-1

[26] Bannayan, M. and Hoogenboom, G. (2008) Weather Analogue: A Tool for Real-Time Prediction of Daily Weather Data Realizations Based on a Modified k-Nearest Neighbor Approach. Environmental Modelling \& Software, 23, 703713. http://dx.doi.org/10.1016/j.envsoft.2007.09.011

[27] Semenov, M.A. (2006) Using Weather Generators in Crop Modelling. Acta Horticulturae, 707, 93-100.

[28] Wilks, D.S. (1992) Adapting Stochastic Weather Generation Algorithms for Climate Changes Studies. Climatic Change, 22, 67-84. http://dx.doi.org/10.1007/BF00143344

[29] Bardossy, A. (1998) Generating Precipitation Time Series Using Simulated Annealing. Water Resources Research, 34, 1737-1744.

[30] Semenov, M.A. and Barrow, E.M. (1997) Use of a Stochastic Weather Generator in the Development of Climate Change Scenarios. Climatic Change, 35, 397-414.

[31] Semenov, M.A., Brooks, R.J., Barrow, E.M. and Richardson, C.W. (1998) Comparison of the WGEN and LARS-WG Stochastic Weather Generators for Diverse Climates. Climate Research, 10, 95-107. http://dx.doi.org/10.3354/cr010095

[32] Semenov, M.A. (2008) Simulation of Extreme Weather Events by a Stochastic Weather Generator. Climate Research, 35, 203-212. http://dx.doi.org/10.3354/cr00731

[33] IPCC (2007) Climate Change 2007: Climate Change Impacts, Adaptation and Vulnerability. Cambridge University Press, Geneva.

[34] Al-Ansari, N.A., Abdellatiff, M., Zakaria, S., Mustafa, Y.T. and Knutsson, S. (2014) Future Prospects for Macro Rainwater Harvesting (RWH) Technique in North East Iraq. Journal of Water Resource and Protection, 6, 403-420. http://dx.doi.org/10.4236/jwarp.2014.65041

[35] Semenov, M.A. and Stratonovitch, P. (2010) Use of Multi-Model Ensembles from Global Climate Models for Assessment of Climate Change Impacts. Climate Research, 41, 1-14. http://dx.doi.org/10.3354/cr00836

[36] Semenov, M.A. (2007) Development of High-Resolution UKCIP02-Based Climate Change Scenarios in the UK. 
Agricultural and Forest Meteorology, 144, 127-138. http://dx.doi.org/10.1016/j.agrformet.2007.02.003

[37] Semeov, M.A. and Barrow, E.M. (2002) LARS-WG-A Stochastic Weather Generator for Use in Climate Impact Studies. Version 3.0 User Manual, Rothamsted Research, Harpenden, Hertfordshire AL5 2JQ, UK, 27 p. 
Scientific Research Publishing (SCIRP) is one of the largest Open Access journal publishers. It is currently publishing more than 200 open access, online, peer-reviewed journals covering a wide range of academic disciplines. SCIRP serves the worldwide academic communities and contributes to the progress and application of science with its publication.

Other selected journals from SCIRP are listed as below. Submit your manuscript to us via either submit@scirp.org or Online Submission Portal.
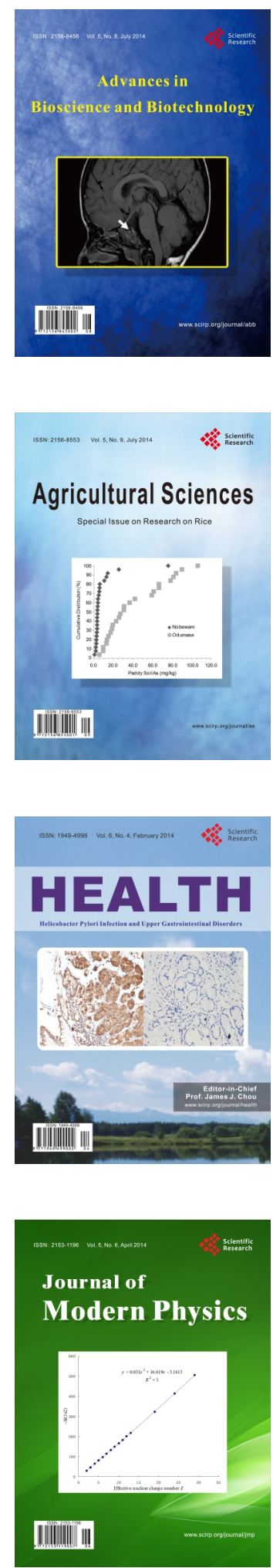
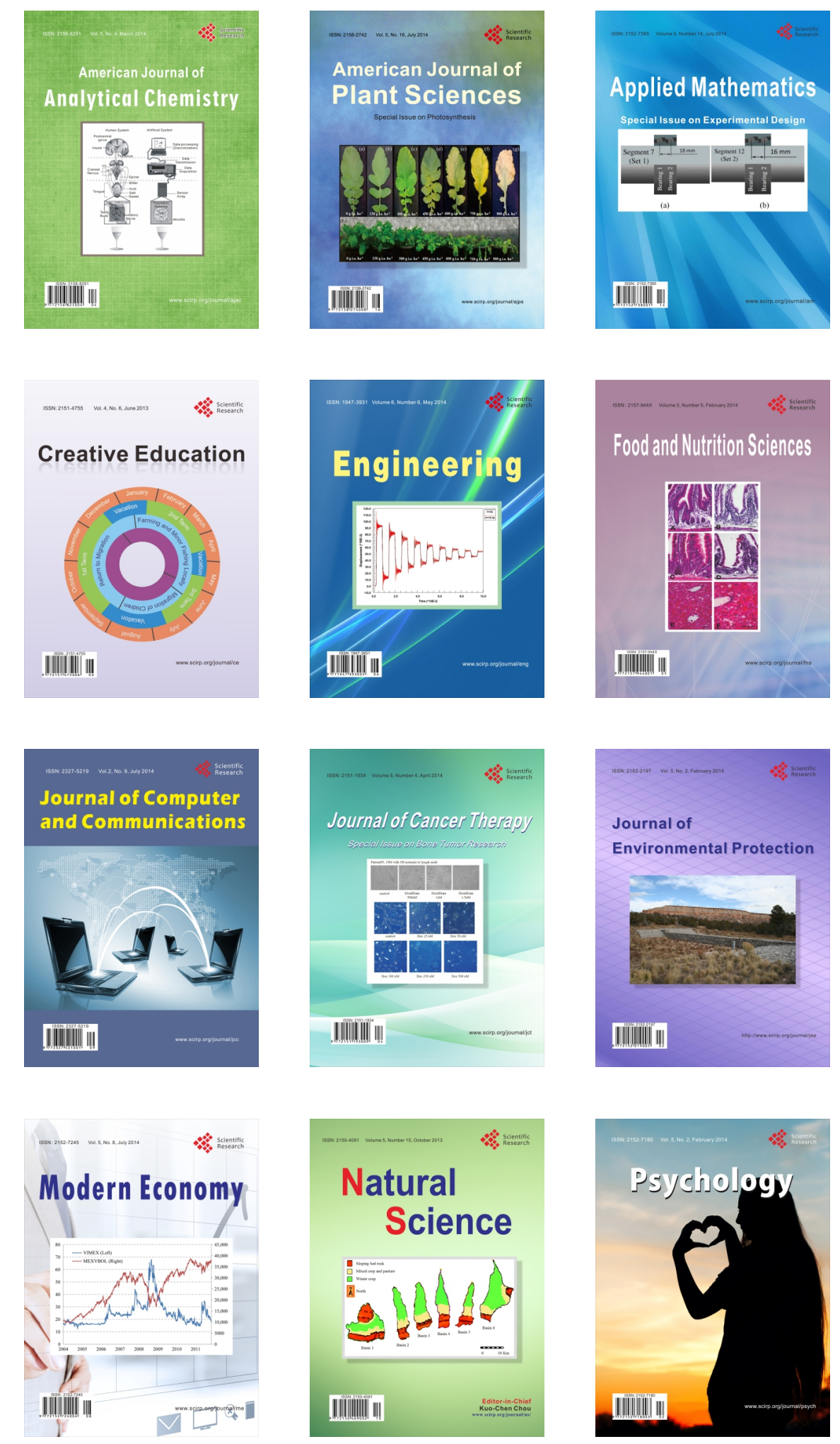